\title{
A High-Fiber Diet Does Not Protect Against Asymptomatic Diverticulosis
}

\author{
Anne F. Peery ${ }^{\star}$, Patrick R. Barrett ${ }^{\star}$, Doyun Park ${ }^{*}, \neq$, Albert J. Rogers ${ }^{\star}$, Joseph A. Galanko*, \\ Christopher F. Martin*, and Robert S. Sandler ${ }^{*}$ \\ *Department of Medicine, University of North Carolina School of Medicine, Chapel Hill, North \\ Carolina \\ ¥Department of Medicine, Albert Einstein College of Medicine, Bronx, New York
}

\begin{abstract}
BACKGROUND \& AIMS-The complications of diverticulosis cause considerable morbidity in the United States; health care expenditures for this disorder are estimated to be $\$ 2.5$ billion per year. Many physicians and patients believe that a high-fiber diet and frequent bowel movements prevent the development of diverticulosis. Evidence for these associations is poor. We sought to determine whether low-fiber or high-fat diets, diets that include large quantities of red meat, constipation, or physical inactivity increase risk for asymptomatic diverticulosis.
\end{abstract}

METHODS-We performed a crosssectional study of 2104 participants, 30-80 years old, who underwent outpatient colonoscopy from 1998 to 2010. Diet and physical activity were assessed in interviews using validated instruments.

RESULTS-The prevalence of diverticulosis increased with age, as expected. High intake of fiber did not reduce the prevalence of diverticulosis. Instead, the quartile with the highest fiber intake had a greater prevalence of diverticulosis than the lowest (prevalence ratio $=1.30 ; 95 \%$ confidence interval, 1.13-1.50). Risk increased when calculated based on intake of total fiber, fiber from grains, soluble fiber, and insoluble fiber. Constipation was not a risk factor. Compared to individuals with $<7$ bowel movements per week, individuals with $>15$ bower movements per week had a $70 \%$ greater risk for diverticulosis (prevalence ratio $=1.70 ; 95 \%$ confidence interval, 1.24-2.34). Neither physical inactivity nor intake of fat or red meat was associated with diverticulosis.

CONCLUSIONS-A high-fiber diet and increased frequency of bowel movements are associated with greater, rather than lower, prevalence of diverticulosis. Hypotheses regarding risk factors for asymptomatic diverticulosis should be reconsidered.

\section{Keywords}

Epidemiology; Exercise; Colon; Intestine; Foods; Nutrition; Incidence

\footnotetext{
(C) 2012 by the AGA Institute

Reprint request Address requests for reprints to: Robert S. Sandler, MD, MPH, University of North Carolina School of Medicine, CB\#7555, Chapel Hill, North Carolina 27599-7555. rsandler@med.unc.edu; fax: (919) 966-9185.

Supplementary Material

Note: To access the supplementary material accompanying this article, visit the online version of Gastroenterology at www.gastrojournal.org, and at doi:10.1053/j.gastro.2011.10.035.

Conflicts of interest

The authors disclose no conflicts.
} 
A third of adults older than the age of 60 years are thought to have asymptomatic diverticulosis. ${ }^{1}$ Of these, $10 \%-40 \%$ will develop complications of their disease, including diverticulitis, abscess, perforation, peritonitis, fistula, obstruction, and hemorrhage. ${ }^{2,3}$ Complications lead to substantial morbidity and mortality. For perforation alone, the 1-year mortality is $19 \% .^{4}$ In 2004 , diverticular disease was responsible for 313,000 hospitalizations, 1.9 million ambulatory care visits, and 3365 deaths in the United States. ${ }^{5}$ Spending on diverticular disease in the United States has been estimated at 2.5 billion dollars per year. ${ }^{6}$

Risk factors for asymptomatic diverticulosis are poorly understood and inadequately studied. Although a lowfiber diet is widely accepted as the etiology for asymptomatic diverticulosis, ${ }^{7,8}$ earlier studies have been limited by selection bias, inadequate accounting for confounding variables, and failure to confirm the presence or absence of diverticulosis. ${ }^{9-11}$ The evidence is similarly weak for additional purported risk factors for diverticulosis, including high intake of red meat and fat, physical inactivity, and constipation.

Understanding the etiology of diverticulosis is the first step in decreasing the risk of diverticulosis complications. The widespread use of colonoscopy has created an opportunity to assemble a population with known asymptomatic diverticulosis. To learn more about risk factors associated with diverticulosis, we analyzed comprehensive data from a colonoscopybased study that collected detailed information on diet, physical activity, and bowel habits. ${ }^{12-14}$ We hypothesized that diet (eg, low-fiber, highfat, high red meat), constipation, and physical inactivity would be associated with an increased risk of diverticulosis.

\section{Methods}

The Diet and Health Studies, Phases III-V (DHS) were cross-sectional studies to assess environmental and lifestyle factors associated with colorectal adenomas. The study methods have been published in detail elsewhere, ${ }^{12-14}$ but are summarized here in brief. The DHS recruited patients undergoing an outpatient colonoscopy at the University of North Carolina Hospitals in Chapel Hill, North Carolina. DHS III was conducted between1998 and 2000, DHS IV between 2001 and 2002, and DHS V between 2009 and 2010. The most common indications for colonoscopy in DHS III $(n=680)$ were average risk colorectal cancer screening, positive family history of colorectal cancer or polyps, or bleeding (occult blood in stool or red blood). The most common indications for colonoscopy in DHS IV $(n=619)$ were average risk colorectal cancer screening or positive family history of colorectal cancer or polyps. DHS V $(n=805)$ included only patients with a screening indication. All participants gave informed consent. Eligible participants were between the ages of 30 and 80 years, with satisfactory preparation for colonoscopy and a complete examination to the cecum. The DHS excluded patients with a history of previous colon resection or a diagnosis of polyposis, colitis, or colon cancer. Participants with an earlier colonoscopy (but no earlier adenomas) were included in DHS III, but excluded from DHS IV and V. The DHS did not exclude a history of diverticular disease.

A research assistant measured height and weight at the time of colonoscopy. Within 12 weeks after colonoscopy, each patient received a phone call from a trained interviewer who was blinded to the colonoscopy results. Interviewers collected information on diet, bowel habits, physical activity, age, sex, race, smoking history, alcohol use, nonsteroidal antiinflammatory drug (NSAID) use, laxative use, and comorbidities.

Dietary information in the DHS III was collected using the Block Diet History Questionnaire, a food frequency questionnaire with 100 food items. ${ }^{15}$ Dietary information in 
the DHS IV and V was collected using the National Cancer Institute Diet History Questionnaire, a food frequency questionnaire with 124 food items. ${ }^{16}$ Participants were asked to report their usual diet during the 1 year before their colonoscopy to avoid seasonal variation in diet.

Physical activity in the DHS III and IV was measured for occupational, nonoccupational, and nonwork/weekend activities using a modified version of a validated 7-day physical activity recall. ${ }^{17}$ Physical activity in the DHS V was measured using the validated International Physical Activity Questionnaire. ${ }^{18}$ All physical activity was classified by metabolic equivalents (METs). Because the raw METs are not equivalent as measured by the 2 different physical activity instruments, METs were categorized in quartiles for analysis purposes. Mean physical activity for each quartile and in each study is presented in Supplementary Table 1. Bowel habits in DHS III, IV and V were assessed with the question, "How many bowel movements do you have each day or week?"

\section{Study Population}

We analyzed data on 2104 participants from DHS III-V who completed the diet interview. Cases were defined as participants found to have any diverticula noted in the colonoscopy record. Controls were those without diverticula noted on their colonoscopy report. The presence and number of colonic diverticula (if recorded) were abstracted from DHS colonoscopy reports by research assistants who were trained in data abstraction and were blinded to the exposure variables. The UNC School of Medicine Institutional Review Board approved both the parent studies and this secondary analysis. The STROBE (Strengthening the Reporting of Observational Studies in Epidemiology) guidelines for reporting descriptive observational studies were followed. ${ }^{19}$

\section{Data Analysis}

Means and standard deviations were reported for continuous variables. Medians were reported for skewed distributions of continuous variables. Proportions were reported for categorical data.

Regular NSAID use was defined as $>15$ times per month. Smoking history was defined as the total number of years smoked. Laxative use was defined as any history of laxative use.

Because the dietary and physical activity instruments differed in the 3 DHS studies, the continuous physical activity (METs) and dietary data were converted into categories (quartiles) generated separately in each study. The assumption of linearity was assessed for all exposure variables. The relationship between diverticulosis and bowel movements per week was not linear, so categorical indictor variables were created to model bowel movements per week.

Unadjusted analyses were performed using logistic regression to assess the association between diet (eg, total fiber, fiber from grains, fiber from beans, fiber from fruits and vegetables, insoluble fiber, soluble fiber, red meat, total fat), physical activity, bowel movements per week and status. Heterogeneity of the association with exposures by age, sex, race, body mass index (BMI), NSAID use, endoscopists, and smoking history was assessed using likelihood ratio tests. No effect modifiers were identified. The $10 \%$ changein-estimate approach was used to assess the following variables for confounding: age, sex, race, BMI, NSAID use, smoking history, history of laxative use, endoscopists, and alcohol intake. Fiber, dietary fat, and red meat intake were adjusted for total caloric intake using linear regression. ${ }^{20}$ The final analyses were performed using Poisson regression to estimate a prevalence ratio. ${ }^{21} \mathrm{We}$ used Poisson regression rather than logistic regression because the 
outcome, diverticulosis, was common ( $>10 \%)$. Poisson regression is a more conservative statistical approach.

In order to further evaluate dose-response, we conducted an analysis stratified by number of diverticula. We compared those participants with a record of few diverticula (ie, 1, 2, or 3 diverticula) to many diverticula (ie, many, several, or $\geq 3$ diverticula). We reasoned that if an exposure increased risk for diverticula, the risk would be higher among subjects with a record of many diverticula than few diverticula.

All tests of significance were 2-tailed and $P<.05$ were considered significant. All data were entered into and analyzed using Stata 11.0 statistical software (StataCorp, College Station, TX).

\section{Results}

There were 2104 participants; 878 cases of diverticulosis and 1226 controls without diverticula noted in their colonoscopy reports. Of the participants with diverticulosis, 246 $(28 \%)$ had a record of many ( 33 ) diverticula, $354(40 \%)$ had few (1 or 2), and the remaining $278(32 \%)$ did not have their diverticular disease quantified. Participants with diverticulosis were more likely to be older, white, overweight or obese, to use tobacco, and to take NSAIDS compared with those without diverticula (Table 1). As expected, the prevalence of diverticulosis increased with age (Figure 1).

High dietary fiber intake was not associated with a reduced prevalence ratio of diverticulosis (Table 2). Instead, we found an increased prevalence of diverticulosis (prevalence ratio [PR] $=1.30 ; 95 \%$ confidence interval $[\mathrm{CI}], 1.13-1.50$ ) comparing the highest quartile of total fiber intake to the lowest, after adjustment for potential confounders (eg, age, race, BMI). This association was dose-dependent; $P$ for trend .004 . Mean total fiber intake in the highest quartile of DHS III was $21.80 \mathrm{~g}$, DHS IV was $33.38 \mathrm{~g}$, and DHS V was $34.46 \mathrm{~g}$ (Table 3). Mean fiber intake in the lowest quartile of DHS III was $6.43 \mathrm{~g}$, DHS IV $10.61 \mathrm{~g}$, and DHS V $11.48 \mathrm{~g}$. In each study, the lowest quartile was used as the reference.

Similarly, we found a higher prevalence for high grain fiber intake ( $\mathrm{PR}=1.25 ; 95 \% \mathrm{CI}$, 1.09-1.45), high soluble fiber intake ( $\mathrm{PR}=1.24 ; 95 \% \mathrm{CI}, 1.07-1.42$ ), and high insoluble fiber intake ( $\mathrm{PR}=1.24 ; 95 \% \mathrm{CI}, 1.08-1.42$ ). These associations held in an analysis limited to DHS IV and V, studies that excluded subjects with an earlier colonoscopy and used the same dietary instrument (total fiber, $\mathrm{PR}=1.28 ; 95 \% \mathrm{CI}, 1.07-1.52$; fiber from grains, $\mathrm{PR}=$ $1.24 ; 95 \% \mathrm{CI}, 1.04-1.48$; soluble fiber, $\mathrm{PR}=1.20 ; 95 \% \mathrm{CI}, 1.01-1.42$; insoluble fiber, $\mathrm{PR}=$ $1.23 ; 95 \%$ CI, 1.04-1.46).

We found no associations between fat intake ( $\mathrm{PR}=0.97 ; 95 \% \mathrm{CI}, 0.84-1.12$ ), red meat intake (PR $=1.04 ; 95 \% \mathrm{CI}, 0.90-1.19)$, or physical activity ( $\mathrm{PR}=1.02$; 95\% CI, 0.89-1.18) and diverticulosis when comparing the highest quartile of each exposure to the lowest, after adjustment for potential confounders (eg, age, race, BMI). In an exploratory analysis, we found no associations between NSAID use (PR $=1.1$; 95\% CI, 0.99-1.22) and diverticulosis after adjustment for age.

We conducted a stratified analysis based on number of diverticula. There was no association between total fiber intake, fiber by any subtype, fat, red meat, and physical activity for few diverticula ( 1 or 2) (Table 4). However, high total fiber intake was associated with an increased prevalence of $\geq 3$ diverticula $(\mathrm{PR}=1.81 ; 95 \% \mathrm{CI}, 1.30-2.52)$. Fiber subtypes that were significantly associated with having $\geq 3$ diverticula included grains $(\mathrm{PR}=1.49 ; 95 \%$ CI, 1.09-2.04), insoluble fiber ( $\mathrm{PR}=1.64 ; 95 \% \mathrm{CI}, 1.18-2.28)$, and soluble fiber ( $\mathrm{PR}=$ $1.74 ; 95 \%$ CI, 1.24-2.45). Having many diverticula was not associated with fiber from 
beans, fiber from fruits and vegetables, intake of total fat or red meat, or physical activity (Table 4).

Contrary to expectation, constipation was not associated with a higher prevalence of diverticulosis (Table 5). Instead, compared to individuals with less frequent $(<7)$ bowel movements per week, those having 7 bowel movements had a higher prevalence $(\mathrm{PR}=1.34$; 95\% CI, 1.04-1.72), as did those with 8-14 bowel movements per week ( $\mathrm{PR}=1.59 ; 95 \%$ $\mathrm{CI}, 1.22-2.07)$, and $>15$ bowel movements per week ( $\mathrm{PR}=1.70$; 95\% CI, 1.24-2.34) after adjustment for potential confounders (eg, age, tobacco use); $P$ for trend $<.001$. There was no association between bowel movement frequency and fiber intake (PR $=0.96 ; 95 \%$ CI, 0.901.02) comparing those with $<7$ bowel movements per week with $\geq 7$ bowel movements per week adjusting for sex and BMI.

\section{Discussion}

In this colonoscopy-based study, a high-fiber diet did not protect against asymptomatic diverticulosis. Instead, we found that a high-fiber diet was associated with a higher prevalence of diverticula. The association was both dose-dependent and stronger when limited to cases with $\geq 3$ diverticula. The risk was increased for total fiber, fiber from grains, soluble fiber, and insoluble fiber. Although constipation is conventionally thought to predispose to diverticulosis, we found that less frequent bowel movements were associated with a decreased prevalence of diverticulosis. No associations were found between the presence of diverticulosis and red meat intake, fat intake, or physical activity. The only expected finding was that the prevalence of diverticulosis increased with age.

Painter and Burkitt introduced the hypothesis that a low-fiber diet was responsible for development of diverticulosis in the late $1960 \mathrm{~s}^{22}$ They reasoned that a lowfiber diet caused excessive colonic pressures resulting in herniation of the mucosa through the muscle wall. ${ }^{22}$ The hypothesis originated with the observation that diverticulosis was rare in native Africans, who were presumed to consume a high-fiber, less refined diet than Westerners. ${ }^{22}$ Painter and Burkitt, however, failed to account for both the longer life expectancy in developed countries and the true diversity of the African diet. ${ }^{23}$ Furthermore, this sort of ecological observation has been shown to be prone to fallacy ${ }^{24}$.

Subsequent observational studies that have evaluated the dietary fiber-diverticulosis hypothesis have had important limitations. All found that a low-fiber diet was associated with diverticulosis. In Brodribb and Humphries, ${ }^{9}$ unblinded hospital dietitians interviewed patients with symptoms and barium enema findings of diverticular disease and estimated their dietary fiber intake. The same dietitian identified an age- and sex matched set of orthopedic visitors and geriatric visitors to the hospital unit. The absence of diverticular disease in the controls was not confirmed.

Miettinen and Tarpila ${ }^{10}$ compared subjects reporting symptoms of diverticular disease to healthy volunteers. Diverticulosis was never directly confirmed in the disease population and it was never ruled out in the healthy volunteers. Gear et al ${ }^{11}$ compared healthy vegetarian controls from a local society to patients selected from lists of general practitioners. Participants ingested $120 \mathrm{~mL}$ barium sulfate 5 days before a single supine radiograph of the abdomen. While this is the only study of diet and diverticulosis that was limited to asymptomatic patients, the authors did not account for race, BMI, or the manner of subject selection, despite the specific concern of comparing "healthy" controls to patients in the care of a physician. The patients were older than the controls.

Few other risk factors for diverticulosis have been studied. Manousos and colleagues ${ }^{25}$ concluded that high meat intake and low vegetable intake were associated with diverticular 
disease in a study of diverticulosis with cases confirmed by barium enema and unevaluated controls from the orthopedic service. Sedentary behavior (but not physical activity or obesity) was associated with an in- creased risk of asymptomatic diverticulosis in a subanalysis of a large observational study of men. ${ }^{26,27}$

In contrast to earlier studies, all of our subjects underwent complete colonoscopy to identify diverticula anywhere in the colon. Although we believe that colonoscopy is an accurate technique to identify diverticula, we are aware of no studies that have determined the accuracy of colonoscopy compared to a gold standard. It is our judgment that diverticula are likely to be present when an endoscopy report notes diverticula (specificity). Because the incidental finding of diverticula might not be noted in colonoscopy reports, the presence and number of diverticula may have been under-reported. We would not expect that diverticulosis would be differentially reported with respect to exposure status. Nondifferential misclas-sification should result in a bias toward the null. As such, our data may underestimate the association between diverticulosis and diet, physicafl activity, and bowel habits.

The present study focused on asymptomatic diverticulosis. Well-designed studies have examined a number of potential risk factors for symptomatic diverticulosis, specifically diverticulitis and bleeding. ${ }^{26-33}$ In contrast to our findings, Aldoori and colleagues ${ }^{31}$ found that a high-fiber diet decreased the risk of symptomatic diverticular complications. The explanation for the discrepant findings is uncertain. It is possible that the risk factors for developing diverticulosis and developing complications of infection and bleeding are different. Our results support this hypothesis and could have implications for prevention.

We used validated quantitative food frequency questionnaires to obtain information on the full range of diet. We examined overall fiber, as well as fiber subtypes, as some research has suggested that insoluble fiber may be more protective. ${ }^{22}$ While food frequency questionnaires are the most convenient assessment in nutritional epidemiology, they are imperfect and subject to measurement error. ${ }^{34}$ We would again expect that misclassification would not be differential. The diet-diverticulosis association may have been underestimated due to this potential misclassification.

Another potential source of bias is the temporal sequence of the colonoscopy and the diet interview. The colonoscopy results were discussed with the patient immediately after the procedure. If the patient were aware of the diverticulosis diagnosis and aware of the fiberdiverticulosis hypothesis, the patient may have altered their reported dietary habits. However, fiber intake was derived from a questionnaire with 100 to 124 food items (eg, pasta salad, muffin, pizza) and this format makes it more difficult to bias fiber intake. Because participants with a possible history of colonoscopy (and thus knowledge of diverticular disease) were included in DHS III, but excluded from DHS IV and V, we were able to assess for this potential bias in an analysis limited to DHS IV and V. The associations in this subanalysis were unchanged from our primary analysis. If previous knowledge of diverticulosis resulted in substantial changes in diet, we would expect the associations to change in the subanalysis.

Although we asked subjects about diet in the past year, most diverticula noted on colonoscopy were almost certainly present for many years based on our prevalence estimates. Despite the long duration of prevalent diverticulosis, we believe that our analysis is valid because the adult diet does not generally change in major ways. ${ }^{35}$ Thus, current diet is a reasonable reflection of past diet. ${ }^{36}$ This analytic approach has been used in hundreds of retrospective studies of dietary risk factors for colorectal neoplasia. ${ }^{37}$ 
We cannot exclude the possibility that people with diverticulosis had symptoms and changed their diet as a consequence. Although such a dietary modification would explain our findings, it is conventionally believed that diverticula do not cause symptoms. We did not observe an increased risk for constipation, and in our study bowel movement frequency was not associated with fiber intake.

The mechanism for the formation of diverticula is unknown. The most widely accepted hypothesis, which we dispute, is that a high-fiber diet bulks the stools, increases colon diameter, and decreases intraluminal pressures in accordance with Laplace's law (wall tension $=$ pressure $\times$ radius). ${ }^{38,39}$ According to this hypothesis, high pressure and colonic segmentation cause the mucosa to herniate through weak areas in the wall to cause diverticula. However, the high-pressure/pulsion hypothesis would not explain right-sided diverticula. Diverticula are not uncommon in the proximal colon, where the bowel diameter is large and increased muscular contraction is not seen. ${ }^{40}$ Gut bacteria could be plausibly related to diverticulosis. The bacterial flora is important for the function and integrity of the epithelial barrier and its blood supply, and is essential for the development of gut motility. ${ }^{41}$ Local quantitative and qualitative changes in gut microbes could potentially induce inflammatory or neuromuscular changes associated with diverticulosis. Dietary fiber could alter gut bacteria.

Practice guidelines recommend a diet high in fruit and vegetable fiber to prevent the development of colonic diverticulosis. ${ }^{42}$ The American Dietetic Association recommends that women consume $25 \mathrm{~g}$ dietary fiber and men consume $38 \mathrm{~g}$ dietary fiber per day. ${ }^{43}$ Current reviews and texts routinely state that inadequate dietary fiber is the widely accepted etiology for diverticulosis. ${ }^{7,8,44-46}$ The evidence supporting these conclusions is poor and, based on our study, needs to be re-examined.

Thirty years ago, Almy and Howell ${ }^{47}$ stated that "important contradictions have emerged and major gaps in our understanding of [diverticulosis] pathogenesis have been revealed." Given the cost of caring for patients with diverticulosis complications, they concluded that diverticulosis research "deserves a higher priority than it has received." 47 In the interim, our understanding of the pathogenesis and risk factors for diverticulosis has not changed and the cost of the disease has increased substantially.

In conclusion, we found that a high-fiber diet and more frequent bowel movements were associated with an increased rather than a decreased prevalence of diverticulosis. Our data demonstrated no association between fat, red meat, physical activity, and diverticulosis. Based on our results, previous hypotheses regarding diverticulosis risk factors and diet recommendations to patients should be reconsidered.

\title{
Supplementary Material
}

Refer to Web version on PubMed Central for supplementary material.

\section{Acknowledgments}

\author{
Funding \\ This research was supported by grants from the National Institutes of Health (P30 DK034987; T32 DK07634, R01 \\ CA44684).
}




\section{Abbreviations used in this paper}

$\begin{array}{ll}\text { BMI } & \text { body mass index } \\ \text { CI } & \text { confidence interval } \\ \text { DHS } & \text { Diet and Health Studies } \\ \text { MET } & \text { metabolic equivalent } \\ \text { NSAID } & \text { nonsteroidal anti-inflammatory drug } \\ \text { PR } & \text { prevalence ratio }\end{array}$

\section{References}

1. Parks TG. Post-mortem studies on the colon with special reference to diverticular disease. Proc R Soc Med. 1968; 61:932-934. [PubMed: 5679019]

2. Parks TG. Natural history of diverticular disease of the colon. Clin Gastroenterol. 1975; 4:53-69. [PubMed: 1109820]

3. Horner JL. Natural history of diverticulosis of the colon. Am J Dig Dis. 1958; 3:343-350. [PubMed: 13520671]

4. Humes DJ, Solaymani-Dodaran M, Fleming KM, et al. A populationbased study of perforated diverticular disease incidence and associated mortality. Gastroenterology. 2009; 136:1198-1205. [PubMed: 19185583]

5. Everhart JE, Ruhl CE. Burden of digestive diseases in the United States part II: lower gastrointestinal diseases. Gastroenterology. 2009; 136:741-754. [PubMed: 19166855]

6. Sandler RS, Everhart JE, Donowitz M, et al. The burden of selected digestive diseases in the United States. Gastroenterology. 2002; 122:1500-1511. [PubMed: 11984534]

7. Sheth AA, Longo W, Floch MH. Diverticular disease and diverticulitis. Am J Gastroenterol. 2008; 103:1550-1556. [PubMed: 18479497]

8. Jacobs DO. Clinical practice. Diverticulitis. N Engl J Med. 2007; 357:2057-2066. [PubMed: 18003962]

9. Brodribb AJ, Humphreys DM. Diverticular disease: three studies. Part I-Relation to other disorders and fibre intake. Br Med J. 1976; 1:424-425. [PubMed: 1252774]

10. Miettinen TA, Tarpila S. Fecal beta-sitosterol in patients with diverticular disease of the colon and in vegetarians. Scand J Gastroenterol. 1978; 13:573-576. [PubMed: 705252]

11. Gear JS, Ware A, Fursdon P, et al. Symptomless diverticular disease and intake of dietary fibre. Lancet. 1979; 1:511-514. [PubMed: 85104]

12. Guilera M, Connelly-Frost A, Keku TO, et al. Does physical activity modify the association between body mass index and colorectal adenomas? Nutr Cancer. 2005; 51:140-145. [PubMed: 15860435]

13. Vinikoor LC, Schroeder JC, Millikan RC, et al. Consumption of trans-fatty acid and its association with colorectal adenomas. Am J Epidemiol. 2008; 168:289-297. [PubMed: 18587137]

14. Austin GL, Adair LS, Galanko JA, et al. A diet high in fruits and low in meats reduces the risk of colorectal adenomas. J Nutr. 2007; 137:999-1004. [PubMed: 17374667]

15. Block G. Dietary guidelines and the results of food consumption surveys. Am J Clin Nutr. 1991; 53(Suppl):356S-357S. [PubMed: 1985410]

16. Subar AF, Thompson FE, Kipnis V, et al. Comparative validation of the Block, Willett, and National Cancer Institute food frequency questionnaires: the Eating at America's Table Study. Am J Epidemiol. 2001; 154:1089-1099. [PubMed: 11744511]

17. Richardson MT, Ainsworth BE, Jacobs DR, et al. Validation of the Stanford 7-day recall to assess habitual physical activity. Ann Epidemiol. 2001; 11:145-153. [PubMed: 11164131]

18. Craig CL, Marshall AL, Sjostrom M, et al. International physical activity questionnaire: 12-country reliability and validity. Med Sci Sports Exerc. 2003; 35:1381-1395. [PubMed: 12900694] 
19. Vandenbroucke JP, von Elm E, Altman DG, et al. Strengthening the Reporting of Observational Studies in Epidemiology (STROBE): explanation and elaboration. Ann Intern Med. 2007; 147:W163-Q194. [PubMed: 17938389]

20. Willett W, Stampfer MJ. Total energy intake: implications for epidemiologic analyses. Am J Epidemiol. 1986; 124:17-27. [PubMed: 3521261]

21. Zou G. A modified poisson regression approach to prospective studies with binary data. Am J Epidemiol. 2004; 159:702-706. [PubMed: 15033648]

22. Painter NS, Burkitt DP. Diverticular disease of the colon: a deficiency disease of Western civilization. Br Med J. 1971; 2:450-454. [PubMed: 4930390]

23. Commane DM, Arasaradnam RP, Mills S, et al. Diet, ageing and genetic factors in the pathogenesis of diverticular disease. World J Gastroenterol. 2009; 15:2479-2488. [PubMed: 19468998]

24. Greenland S, Robins J. Invited commentary: ecologic studies— biases, misconceptions, and counterexamples. Am J Epidemiol. 1994; 139:747-760. [PubMed: 8178788]

25. Manousos O, Day NE, Tzonou A, et al. Diet and other factors in the aetiology of diverticulosis: an epidemiological study in Greece. Gut. 1985; 26:544-549. [PubMed: 3924745]

26. Strate LL, Liu YL, Aldoori WH, et al. Obesity increases the risks of diverticulitis and diverticular bleeding. Gastroenterology. 2009; 136:115-122. e1. [PubMed: 18996378]

27. Strate LL, Liu YL, Aldoori WH, et al. Physical activity decreases diverticular complications. Am J Gastroenterol. 2009; 104:1221-1230. [PubMed: 19367267]

28. Strate LL, Liu YL, Syngal S, et al. Nut, corn, and popcorn consumption and the incidence of diverticular disease. JAMA. 2008; 300:907-914. [PubMed: 18728264]

29. Rosemar A, Angeras U, Rosengren A. Body mass index and diverticular disease: a 28-year followup study in men. Dis Colon Rectum. 2008; 51:450-455. [PubMed: 18157570]

30. Aldoori WH, Giovannucci EL, Rimm EB, et al. A prospective study of diet and the risk of symptomatic diverticular disease in men. Am J Clin Nutr. 1994; 60:757-764. [PubMed: 7942584]

31. Aldoori WH. The protective role of dietary fiber in diverticular disease. Adv Exp Med Biol. 1997; 427:291-308. [PubMed: 9361853]

32. Aldoori WH, Giovannucci EL, Rimm EB, et al. Prospective study of physical activity and the risk of symptomatic diverticular disease in men. Gut. 1995; 36:276-282. [PubMed: 7883230]

33. Aldoori WH, Giovannucci EL, Rimm EB, et al. A prospective study of alcohol, smoking, caffeine, and the risk of symptomatic diverticular disease in men. Ann Epidemiol. 1995; 5:221-228. [PubMed: 7606311]

34. Prentice RL. Dietary assessment and the reliability of nutritional epidemiology research reports. J Natl Cancer Inst. 2010; 102:583-585. [PubMed: 20407089]

35. Willett WC, Sampson L, Browne ML, et al. The use of a selfadministered questionnaire to assess diet four years in the past. Am J Epidemiol. 1988; 127:188-199. [PubMed: 3337073]

36. Stryker WS, Kaplan LA, Stein EA, et al. The relation of diet, cigarette smoking, and alcohol consumption to plasma beta-carotene and alpha-tocopherol levels. Am J Epidemiol. 1988; 127:283-296. [PubMed: 3257350]

37. World Cancer Research Fund/American Institute for Cancer Research. Food, nutrition, physical activity and the prevention of cancer: a global perspective. Washington, DC: World Cancer Research Fund/American Institute for Cancer Research; 2007.

38. Painter NS. The cause of diverticular disease of the colon, its symptoms and its complications. Review and hypothesis. J R Coll Surg Edinb. 1985; 30:118-122. [PubMed: 2991507]

39. Aldoori W, Ryan-Harshman M. Preventing diverticular disease. Review of recent evidence on high-fibre diets. Can Fam Physician. 2002; 48:1632-1637. [PubMed: 12449547]

40. Hughes LE. Postmortem survey of diverticular disease of the colon. I. Diverticulosis and diverticulitis. Gut. 1969; 10:336-344. [PubMed: 5771665]

41. Quigley EM. Gut microbiota, inflammation and symptomatic diverticular disease. New insights into an old and neglected disorder. J Gastrointestin Liver Dis. 2010; 19:127-129. [PubMed: 20593043] 
42. Stollman NH, Raskin JB. Diagnosis and management of diverticular disease of the colon in adults. Ad Hoc Practice Parameters Committee of the American College of Gastroenterology. Am J Gastroenterol. 1999; 94:3110-3121. [PubMed: 10566700]

43. American Dietetic Association. [Accessed October 5, 2010] Eat fiber for health. Available at: http://www.eatright.org/Public/content.aspx?id=6796

44. Floch MH, White JA. Management of diverticular disease is changing. World J Gastroenterol. 2006; 12:3225-3228. [PubMed: 16718843]

45. Martel J, Raskin JB. History, incidence, and epidemiology of diverticulosis. J Clin Gastroenterol. 2008; 42:1125-1127. [PubMed: 18936648]

46. Fry, RD.; Mahmoud, N.; Maron, DJ., et al. Diverticular disease. In: Townsend, C., Jr; Beauchamp, RD.; Evers, MB., editors. Sabiston textbook of surgery. 18th ed.. Philadelphia: Saunders; 2007.

47. Almy TP, Howell DA. Medical progress Diverticular disease of the colon. N Engl J Med. 1980; 302:324-331. [PubMed: 6985709] 


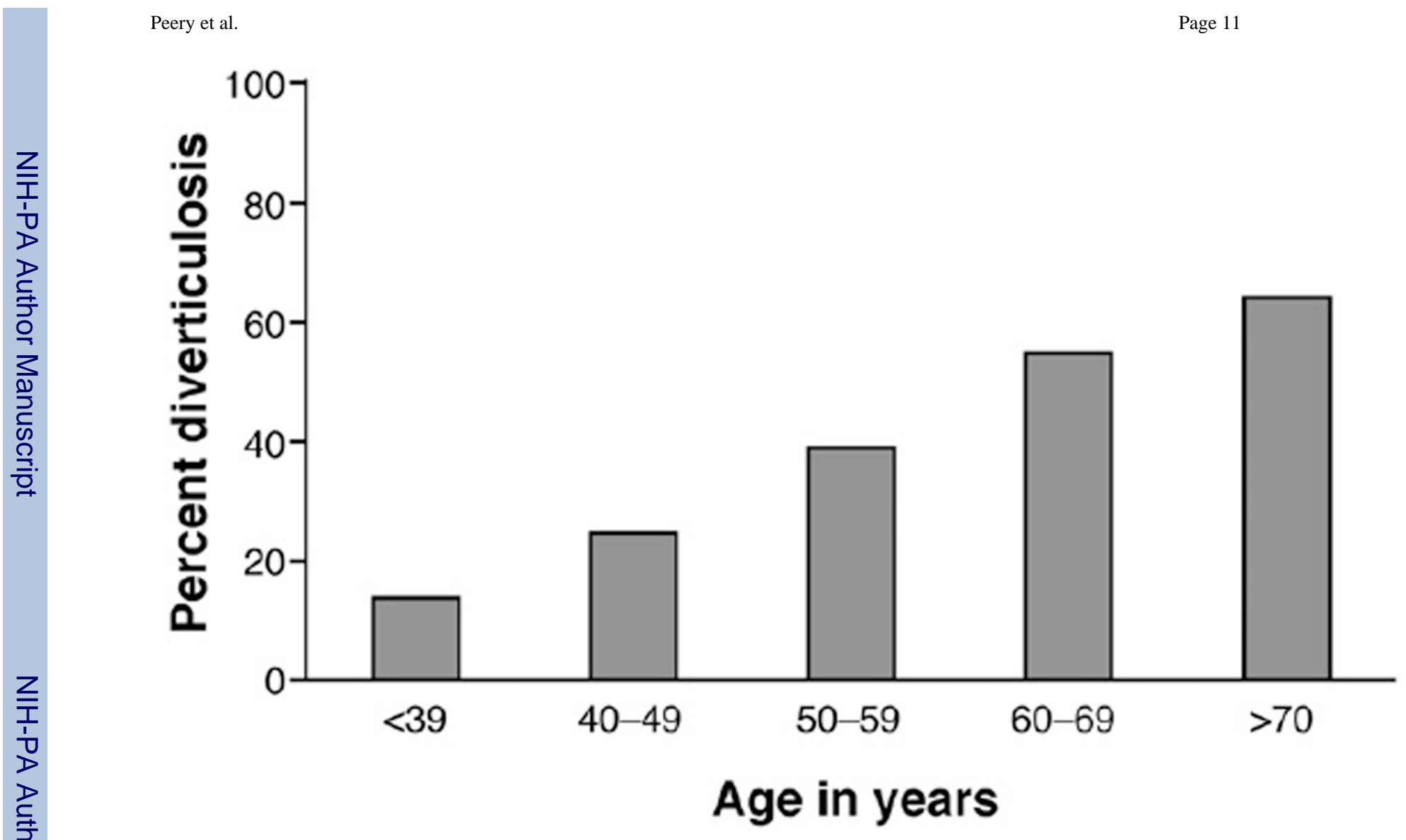

Figure 1.

Prevalence of diverticulosis by age $(\mathrm{n}=878)$. 
Table 1

Characteristics of the Study Population by Case Status $(n=2104)$

\begin{tabular}{|c|c|c|c|}
\hline Characteristics & $\begin{array}{l}\text { Diverticulosis } \\
\quad(\mathbf{n}=878)\end{array}$ & $\begin{array}{l}\text { No diverticulosis } \\
\quad(\mathrm{n}=1226)\end{array}$ & $P$ value \\
\hline Age, $y$ & $58.8 \pm 8.9$ & $53.7 \pm 8.8$ & $<.001$ \\
\hline$<39$ & $10(1)$ & $63(5)$ & \\
\hline $40-49$ & $75(9)$ & $220(18)$ & \\
\hline $50-59$ & $418(48)$ & $664(54)$ & \\
\hline $60-69$ & $253(29)$ & 209 (17) & \\
\hline$>70$ & $122(14)$ & $69(6)$ & \\
\hline Sex, male & $370(42)$ & $514(42)$ & .929 \\
\hline Race, white & $735(84)$ & $971(80)$ & .005 \\
\hline BMI, $\mathrm{kg} / \mathrm{m}^{2}$ & $27.9 \pm 5.8$ & $27.1 \pm 6.1$ & .002 \\
\hline Underweight $(<18.5)$ & $13(2)$ & $22(2)$ & \\
\hline Normal (18.5-25) & $278(33)$ & $505(43)$ & \\
\hline Overweight (25-30) & $307(36)$ & $366(31)$ & \\
\hline Obese $(>30)$ & $245(29)$ & $285(24)$ & \\
\hline Regular NSAID use & $299(34)$ & $314(26)$ & $<.001$ \\
\hline Tobacco use, $y$ & $20.2 \pm 14.0$ & $17.8 \pm 12.9$ & .007 \\
\hline Daily alcohol use, $g$ & $10.0 \pm 25.1$ & $9.3 \pm 27.7$ & .569 \\
\hline Total energy intake, $k c a l / d a y$ & $1826 \pm 809$ & $1824 \pm 799$ & .952 \\
\hline Total fiber, $g /$ day & $18.8 \pm 9.7$ & $18.8 \pm 9.2$ & .917 \\
\hline Bean fiber, $g / d a y$ & $3.4 \pm 3.2$ & $3.4 \pm 2.8$ & .801 \\
\hline Grain fiber, $g /$ day & $6.2 \pm 4.0$ & $6.4 \pm 4.0$ & .156 \\
\hline Fruit and vegetable fiber, $g /$ day & $8.0 \pm 5.0$ & $7.9 \pm 4.9$ & .627 \\
\hline Soluble fiber, $g /$ day & $6.9 \pm 3.2$ & $6.9 \pm 3.1$ & .922 \\
\hline Insoluble fiber, $g /$ day & $13.2 \pm 6.5$ & $13.3 \pm 6.3$ & .777 \\
\hline Red meat, oz/day & $2.6 \pm 2.2$ & $2.6 \pm 2.1$ & .816 \\
\hline Fat, g/day & $70.2 \pm 35.9$ & $69.2 \pm 34.0$ & .545 \\
\hline Bowel movements per week & 7 & 7 & $<.001$ \\
\hline Laxatives use ever & $483(55)$ & $746(61)$ & .008 \\
\hline
\end{tabular}

NOTE. Continuous variables are reported as mean $\pm \mathrm{SD}$, with the exception of bowel movements per week, which are reported as median values given a skewed distribution. Categorical variables are reported as $\mathrm{n}(\%)$. 
Table 3

Range of Dietary Fiber Intake ( $g /$ day) by Study and Quartile

\begin{tabular}{llrrc}
\hline & \multicolumn{4}{c}{ Quartile } \\
\cline { 2 - 5 } & $\mathbf{1}$ & $\mathbf{2}$ & $\mathbf{3}$ & $\mathbf{4}$ \\
\hline DHS III & $1.2-8.7$ & $8.7-12.2$ & $12.2-16.6$ & $16.7-43.1$ \\
DHS IV & $2.9-14.2$ & $14.3-20.0$ & $20.0-26.3$ & $26.4-72.3$ \\
DHS V & $4.0-15.2$ & $15.2-20.4$ & $20.5-26.8$ & $26.8-83.9$ \\
\hline
\end{tabular}


Table 4

Crude and Adjusted ${ }^{a}$ (95\% CI) Prevalence Ratios for Number of Diverticula by Diet and Physical Activity Comparing Highest Quartile to Lowest

\begin{tabular}{|c|c|c|c|}
\hline & All cases $(n=878)$ & Few diverticula $(n=354)$ & Many diverticula $(n=246)$ \\
\hline \multicolumn{4}{|l|}{ Total fiber } \\
\hline Crude & $1.09(0.94-1.25)$ & $1.02(0.79-1.33)$ & $1.25(0.90-1.72)$ \\
\hline Adjusted & $1.30(1.13-1.50)$ & $1.17(0.89-1.54)$ & $1.81(1.30-2.52)$ \\
\hline \multicolumn{4}{|c|}{ Fiber from beans } \\
\hline Crude & $1.00(0.86-1.15)$ & $0.90(0.70-1.17)$ & $1.09(0.78-1.53)$ \\
\hline Adjusted & $1.10(0.95-1.27)$ & $0.97(0.74-1.26)$ & $1.34(0.95-1.88)$ \\
\hline \multicolumn{4}{|c|}{ Fiber from grains } \\
\hline Crude & $1.09(0.94-1.26)$ & $1.19(0.91-1.57)$ & $1.10(0.80-1.50)$ \\
\hline Adjusted & $1.25(1.09-1.45)$ & $1.31(0.99-1.72)$ & $1.49(1.09-2.04)$ \\
\hline \multicolumn{4}{|c|}{ Fiber from fruits and vegetables } \\
\hline Crude & $0.90(0.78-1.04)$ & $0.98(0.75-1.29)$ & $0.77(0.56-1.06)$ \\
\hline Adjusted & $1.06(0.92-1.22)$ & $1.07(0.81-1.43)$ & $1.06(0.77-1.46)$ \\
\hline \multicolumn{4}{|c|}{ Insoluble fiber } \\
\hline Crude & $1.03(0.90-1.18)$ & $1.00(0.78-1.29)$ & $1.10(0.80-1.51)$ \\
\hline Adjusted & $1.24(1.08-1.42)$ & $1.15(0.88-1.50)$ & $1.64(1.18-2.28)$ \\
\hline \multicolumn{4}{|c|}{ Soluble fiber } \\
\hline Crude & $1.04(0.91-1.20)$ & $0.93(0.72-1.20)$ & $1.22(0.88-1.70)$ \\
\hline Adjusted & $1.24(1.07-1.42)$ & $1.06(0.81-1.40)$ & $1.74(1.24-2.45)$ \\
\hline \multicolumn{4}{|l|}{ Total fat } \\
\hline Crude & $0.96(0.83-1.11)$ & $0.98(0.76-1.26)$ & $1.00(0.74-1.34)$ \\
\hline Adjusted & $0.97(0.84-1.12)$ & $0.99(0.76-1.30)$ & $1.02(0.75-1.38)$ \\
\hline \multicolumn{4}{|l|}{ Red Meat } \\
\hline Crude & $1.03(0.89-1.19)$ & $1.04(0.80-1.35)$ & $1.02(0.74-1.41)$ \\
\hline Adjusted & $1.04(0.90-1.19)$ & $1.04(0.80-1.36)$ & $1.07(0.78-1.47)$ \\
\hline \multicolumn{4}{|c|}{ Physical activity } \\
\hline Crude & $0.85(0.74-0.98)$ & $0.84(0.65-1.09)$ & $0.91(0.66-1.27)$ \\
\hline Adjusted & $1.02(0.89-1.18)$ & $0.94(0.72-1.22)$ & $1.24(0.89-1.72)$ \\
\hline
\end{tabular}

${ }^{a}$ Adjusted for age, race, and body mass index. 
